\title{
Analysis on the Theme Expressions in Two Chinese Versions of Pride and Prejudice from the Feminist Perspective
}

\author{
Ruiqi Qiao ${ }^{1, *}$ \\ ${ }^{1}$ School of Humanities, Beijing University of Posts and Telecommunications, Beijing 100876, China \\ "Corresponding author. Email: 140105200007070023@bupt.edu.cn
}

\begin{abstract}
As a full-fledged classic, Pride and Prejudice, written by English novelist Jane Austen, has a unique and nonnegligible impact on generations with its outstanding artistry and profound ideas. The work contains themes of gender and women's self-growth, manifesting Jane Austen's central opinion that it is unwise to marry just for worldly fame and wealth and that it is also foolish to marry without putting these into consideration. She considers love as the cornerstone of an ideal marriage. Furthermore, Jane Austen expresses the pursuit of women's rights in legal, economic and social aspects, with an appeal to women's aspirations for equality. The novel has a certain impact on the awakening of women's consciousness and reshaping women's perceptions of choosing their spouses, breaking the subjugation of women's social consciousness in the patriarchal society. However, if this wonderful work is to fulfil its superbly inspiring role abroad (in this case in China), then the ability and effort of translators are required. It is found that most domestic studies on the translation of Pride and Prejudice have dealt with the influence of context on its translation (e.g. Ren Jing's study on the influence of context on the translation of foreign literary works), the general study of the translation of this work from the perspective of translation criticism (e.g. Chen Ming's study on the mistranslation of Wang Keyi's translation of Pride and Prejudice from the perspective of translation criticism) or the specific translation techniques of this masterpiece (e.g. Chen Yinping and Liu Kai's study on the translation methods and techniques of literature - an appreciation of the translation excerpts of Pride and Prejudice). In general, there are few studies of feminist translations and related feminist themes of this work. Where they do, they focus on the influence of the translator's subjectivity rather than focusing on Jane Austen's original meaning. Thus, this paper studies the themes of Pride and Prejudice - gender and women's self-growth from the feminist perspective. By analyzing the details and differences in presentation style between the two Chinese versions, the influences of the translators' feminine consciousness on the interpretation of the work's themes are explored in order to find a more appropriate translation of Pride and Prejudice, gain some enlightenment about translation and enrich the development of feminist translation in China.
\end{abstract}

Keywords: Pride and Prejudice, Gender, Women's self-growth, Feminist translation studies.

\section{INTRODUCTION}

In Pride and Prejudice, Jane Austen expresses the pursuit of women's rights in legal, economic and social aspects, with an appeal to women's aspirations for equality. She conveys the themes and profound views by portraying women with feminine consciousness. This paper studies two themes of Pride and Prejudice - gender and women's self-growth from the feminist perspective by analyzing and comparing two Chinese versions of this novel. By exploring the differences in detail and presentation style between the two translations, whether the translators have appropriately expressed the feminine consciousness present in the themes of the work are judged and how this work can be more appropriately translated is analyzed, thereby acquiring some enlightenment about literary translation and enriching the development of feminist translation in the local context. 


\section{GENDER}

The central theme embedded in Pride and Prejudice is gender. The story takes place at a period when gender roles were quite rigid, and men and women had a quite different set of roles and influences. Jane Austen elaborates on this theme by depicting different marriages of the five sisters (especially Elizabeth), for marriage was the only way women can achieve economic stability and autonomy (but men have many other approaches). During that time, marriage served as a topic that was widely considered and talked about, and women were often evaluated and assessed in the context. Jane Austen highlights the differences between the two genders by emphasizing the examination of women in the construction of the whole process of marriage, conveying the great importance to ideal marriage and regarding love as the cornerstone of an ideal marriage. Meanwhile, she reveals the status of middle-class women during that moment, encourages women to pursue equality and independence and supports them to courageously seek their ideal love and marriage rather than just being profit-oriented which reflects the missing feminine consciousness in a feudal patriarchal society. There is no doubt that translators have made translations based on the author's feminist thoughts, but they still present different translations especially in its approach to details. For instance:

"But there is one of her sisters sitting down just behind you, who is very pretty... Do let me ask my partner to introduce you. "[1]

This sentence takes place in the early part of the story; when the Elizabeth first met with Darcy and Bentley at a ball, they made few comments on her. In this sentence, the word "pretty" is used to portray a girl as cute, attractive and charming. Sun zhili translates it as "tao ren ai[2]", which is masculine in tone, conveying the idea that male judgement determines how beautiful Elisabeth is. Such a representation weakens female autonomy and increases female subservience. Zhang Ling and Zhang Yang's version translates pretty as "ke ai[3]", which serves as a more objective description and better reflects Jane Austen's emphasis on femininity throughout the work, allowing readers to better understand feminist thinking and judgement. Based on the above comparative analysis, the latter translation follows original meaning more closely.

"Your hope is a rather extraordinary one after my declaration... Nay, were your friend Lady
Catherine to know me, I am persuaded she would find me in every respect ill qualified for the situation." [1]

The version by Sun Zhili: "假使你的朋友凯瑟琳夫 人认识我的话, 我相信她会发觉, 我无论哪方面都不配做你太 太。"[2]

The version by Zhang Ling and Zhang Yang: " 而且, 如果你的朋友凯瑟琳夫人认识我, 我相信, 她会认为 我在任何方面的条件都不适合。"[3]

Here Sun Zhili translates it as "bu pei" and Zhang Ling and Zhang Yang translate it as "bu shi he". In the original, Elizabeth has been described as an independent person with a strong sense of selfesteem, so she does not presume to describe herself as "bu pei". Based on their appreciation of the author's intent and characterization, Zhang Ling and Zhang Yang's translation comes closer to the feminist consciousness that the original intended to convey.

To sum up, Jane Austen uses a feminist perspective when interpreting gender differences, which was definitely resistant and innovative in the 18th and 19th centuries in England when women were asked to be an "angel" in the house[4]. As Tillie Olsen argued that women's voicelessness stems from their "environment": they are born into the wrong class, race, and gender, rejected by education, numbed by economic constraints, gagged by censorship, and hindered and distracted by child-rearing[5]. Under these circumstances, Jane Austen's work was definitely a powerful expression of feminism and an appeal to women's aspirations for equality. The translation of these two cases, which illustrate the themes of love and marriage, reveals that the translation plays an integral role in the presentation of the themes and the reader's perception of the work. Zhang Yang and Zhang Ling's version is better aligned with the original work in terms of detail and overall style, and better allows Chinese readers to appreciate the feminist spirit.

\section{WOMEN'S SELF-GROWTH}

Pride and Prejudice explored the psychological growth of the heroine Elizabeth from falling in love to getting married. As is demonstrated in The Second Sex, "Representation of the world, like the world itself, is the work of men; they describe it from their own point of view, which they confuse with absolute truth."[6] It is worth noting that Jane Austen constructed a new narrative pattern from the unique female point of view, that is, most of the 
novel's narrative was based on the heroine's psychological changes which were considered as the core of the development of the plot. A vital piece of the narrative that demonstrates Elizabeth's psychological maturation and overcoming of her pride and prejudice serves as the chat between Elizabeth and her father after Mr. Darcy and Elizabeth's father have finished talking. This episode occurs near the end of the story: Darcy came to Elizabeth's family home, telling her father that he wanted to marry Elizabeth. The father, seeing that Darcy had "condescended to him", did not refuse his proposal. But for the sake of his beloved daughter's happiness, he did not approve of the marriage sincerely at this time. He thought that Elizabeth did not appreciate Darcy, let alone love him. It would be a complete tragedy for her married life if this vivacious and intelligent girl was to take as her husband a man whom she did not respect or admire. Thus, in the subsequent chat between Elizabeth and herself, her father clearly expressed his reasons and concerns, which also side-steps Elizabeth's cognitive development.

The original text is listed as follows:

"Lizzy...He is the kind of man, indeed, to whom I should never dare refuse anything, which he condescended to ask... I know that you could be neither happy nor respectable... unless you looked up to him as a superior. Your lively talents would place you in the greatest danger in an unequal marriage." [1]

In this context, both translations fulfill the "faithfulness", "expressness" and "elegance" required for translation, conveying the author's original intention. For instance, "condescended to" is translated as "qv zun xiang jiu[2]" or "meng ta bu qi[3]"; "superior" is translated as "sheng ni yi chou[2]" or "gao ni yi chou[3]"; "unequal" is translated as "bu neng hu xiang ban pei[2]". The translation demonstrates the father's awareness of Darcy's superior qualifications and conditions, but for him he is more concerned with Elizabeth's happiness and their suitability for each other. He realizes that a happy couple needs to adore and count on each other rather than treat each other with prejudice and compromise. The expression of the translation embodies a sense of equality, placing Elizabeth and Darcy on an equal ground in discussing their relationship. Actually the father's words are interpreted in an unobtrusive and methodical tone, reasoning with the idea of equality rather than expressing his opinion based on the usual thinking that women are subordinate and vulnerable. Then, these words lead to Elizabeth's later response, which demonstrates that Elizabeth did not agree to marry Darcy out of fame or impulse, but overcame her pride and prejudice and truly fell in love with Darcy with sincerity and understanding. These two young people took it into their heads to marry, they were pretty sure by perseverance to carry their point[7]. Her selfgrowth and psychological changes are well shown in the two translated versions.

\section{CONCLUSION}

As a classic that has inspired generations, Pride and Prejudice contains themes and ideas of universal value which are still of great inspiration to contemporary society and women. Through the study of the two themes in two Chinese versions, it can be realized that translators plays a vital role in bridging the gap between the original work and readers. As Madame de Stael had so clearly stated, that movements of literary exchange are vital to the democratic life of any nation[8]. If translators can grasp accurately the feminist consciousness embodied in the work and express it, then the value and essence of the work can be transmitted perfectly for the benefit of a wider audience. This study can help people to pay more attention to the female community and feminist translations in China, and at the same time, it can better spread the promotion of feminism, so that people can understand the extraordinary significance of women in the development of society.

\section{AUTHORS' CONTRIBUTIONS} Qiao.

This paper is independently completed by Ruiqi

\section{REFERENCES}

[1] Jane Austen. Pride and prejudice. Harper Press, 2010.

[2] Sun Zhili. Pride and Prejudice [M]. Nanjing: Yilin Publishing House, 2000.

[3] Zhang Ling, Zhang Yang. Pride and Prejudice [M]. Beijing: People's Literature Publishing House, 1993.

[4] Virginia Woolf. Death of a Moth and Other Essays. HARCOURT BRACE \& CO, 1942.

[5] Tillie Olsen. Silence. The Feminist Press, 2003. 
[6] Simone de Beauvoir. The Second Sex. Cambridge University Press, 2003

[7] Jane Austen. Persuasion. Bantam Classics, 1984.

[8] "Pride and Prejudice": Power, Fantasy, and Subversion in Jane Austen. Judith Lowder Newton. Vol. 4, No. 1 (Feb., 1978), pp. 27-42 (16 pages) 